\title{
Effect of non-aromatizable androgens on testicular and accessory gland functions in rhesus monkeys (Macaca mulatta)
}

\author{
P. R. Ramakrishnan, J. Kaur and M. Rajalakshmi \\ Department of Reproductive Biology, All India Institute of Medical Sciences, \\ New Delhi-110029, India
}

\begin{abstract}
Summary. Adult male rhesus monkeys were injected intramuscularly $100 \mu \mathrm{g}, 1000 \mu \mathrm{g}$ $5 \alpha$-androstane-3 $\alpha, 17 \beta$-diol or $100 \mu \mathrm{g}$ dihydrotestosterone (DHT) per day for 70 days. A decrease in seminiferous tubular diameter was seen in treated animals. Androstanediol treatment disrupted spermatogenesis in most tubules. Sperm motility decreased within 40 days and by Day 70 non-motile spermatozoa were seen in 2 animals of each group treated with androstanediol. DHT treatment also decreased sperm motility progressively from Day 40 . Both androgens caused retention of the cytoplasmic droplet and an increase in coiling of the tail of spermatozoa. Seminal fructose was decreased by Day $40(1000 \mu \mathrm{g}$ androstanediol) or Day $70(100 \mu \mathrm{g}$ androstanediol and $100 \mu \mathrm{g}$ DHT). Seminal glycerophosphocholine (GPC) and acid phosphatase levels decreased by Day 70 in all treatment groups. Both steroids decreased circulating concentrations of testosterone without altering FSH or oestradiol values.
\end{abstract}

Keywords: DHT; androstanediol; testis; semen biochemisty; rhesus monkey

\section{Introduction}

In attempts to develop a safe, effective and reversible contraceptive for males, several steroids either alone or in combination regimens have been tested but none held great promise due to a variety of reasons (Bajaj \& Madan, 1983). Use of testosterone or its esters in these regimens for prolonged periods was undesirable due to its side effects such as weight gain, aggravation or reappearance of acne and reduction in testicular size (Troen, 1977). Alteration of the testosterone-oestradiol ratio and the implications of such alterations were a major cause of concern in using testosterone derivatives on a long-term basis. Androstanediol and DHT are formed from testosterone in equal proportions by isolated human seminiferous tubules (Payne et al., 1973; Rivarola et al., 1973); testicular $3 \alpha$-oxidoreductase acts as a key enzyme converting DHT to androstanediols (Hastings et al., 1980). In view of the inability of DHT and androstanediol to undergo aromatization to oestradiol, these two androgens may have an advantage over testosterone and its esters in studies related to male fertility regulation. The effects of $5 \alpha$-androstane-3 $3,17 \beta$-diol in rats are well known (Schmidt et al., 1973; Kreig et al., 1975; Purvis et al., 1977) but its effects on adult non-human primates are not known. Since recent studies have shown renewed interest in using non-aromatizable androgens for male fertility regulation, we have compared the effects of DHT and androstanediol on pituitary, testicular and accessory gland functions in adult rhesus monkeys.

\section{Materials and Methods}

Animals and experimental design. Sixteen adult male rhesus monkeys (Macaca mulatta), weighing 9-12.5 kg which had undergone quarantine and kept in the Primate Research Facility of AIIMS, were used. 
Before treatment, blood was collected at $10: 00 \mathrm{~h}$ and serum was stored at $-20^{\circ} \mathrm{C}$ until hormone analysis. Semen was collected 1 day later by electroejaculation by the penile method (Mastroianni \& Manson, 1963). The animals were randomized and divided into groups of four. Those in Groups I, II and III were given $100 \mu \mathrm{g}$ androstanediol, $1000 \mu \mathrm{g}$ androstanediol and $100 \mu \mathrm{g}$ DHT, respectively per day in $0.2 \mathrm{ml}$ olive oil as a single intramuscular injection for 70 days. Group IV animals received $0.2 \mathrm{ml}$ olive oil only for 70 days.

Blood was collected on Days 10, 20, 40 and 70 and semen on Days 21, 41 and 71 .

Testicular biopsy was done during the pretreatment period and on Day 72 of treatment under ketamine anaesthesia $(10 \mathrm{mg} / \mathrm{kg}$ body weight; Themis Chemicals Ltd, India). About $5 \mathrm{mg}$ tissue was obtained from the upper half of the anterior border of the testis during the pretreatment period and from the lower half on Day 72 of treatment, fixed in Bouin's fluid and processed for histology. The slides were stained with haematoxylin-eosin. Seminiferous tubules with a circular cross-section were selected per monkey and the diameter of each of 25 tubules/monkey was measured by means of an eye piece graticule.

Sperm count, motility and viability were evaluated according to the WHO Manual (Belsey et al., 1980). Sperm viability was estimated from nigrosin-eosin-stained slides and 100 spermatozoa were counted under the light microscope to differentiate the live (unstained) spermatozoa from the dead (stained) spermatozoa. Sperm morphology and head-tail separation of spermatozoa were assessed in Papanicolau-stained slides.

Assays. Fructose, glycerophosphocholine (GPC) and acid phosphatase were estimated in aliquants of semen homogenate (White, 1959; Lindner \& Mann, 1960; Lindhart \& Walter, 1965).

Serum testosterone and DHT were separated by Celite chromatography (Sjoberg et al., 1979) and analysed by radioimmunoassay (Brenner et al., 1973). The antiserum to testosterone had the following cross-reactivity: cortisol $0.0001 \%, 5 \alpha$-DHT $14 \%$, 4-adrostanedione $0.8 \%, 5 \alpha$-androstanediol $6 \%$ and 5 -androstanediol $2 \cdot 1 \%$. The sensitivity limit expressed as the lowest amount on the linearized standard curve was $34 \mathrm{fmol} /$ tube. The antiserum to DHT had the following cross-reactivity with the steroids localized in the chromatographic fraction: 4-androstene-3,11,17trione, $20 \alpha$-hydroxy-4-pregnen-3-one, 20ß-hydroxy-4-pregnen-3-one and 21-hydroxy-4-pregnene-3,20-dione $<0 \cdot 1 \%$. The sensitivity limit expressed as the lowest amount on the linearized standard curve was $6.25 \mathrm{pg} / \mathrm{tube}$. The intraand inter-assay coefficients of variation were $7 \cdot 3 \%$ and $10 \cdot 2 \%$ for testosterone and $9.8 \%$ and $11.3 \%$ for DHT, respectively. Oestradiol was assayed using the iodinated kit from Isotopen Produktion, Würenlingen, Switzerland. The oestradiol antiserum had the following cross-reactivity: oestrone and oestradiol $2 \%$, ethinyl oestradiol, progesterone, testosterone and androstanediol $<0.1 \%$. The sensitivity limit expressed as the lowest amount on the linearized standard curve was $0.5 \mathrm{pg} /$ tube while intra- and inter-assay coefficients of variation were $5 \cdot 1 \%$ and $6.9 \%$, respectively. FSH was assayed by the heterologous assay system with reagents supplied by the WHO Matched Assay Reagent Programme. The FSH assay used cynomolgus FSH (WP-XV-104C) as standard, anti-ovine FSH antiserum (H 3I) and human FSH tracer (Khan et al., 1984). The sensitivity of the FSH assay, when expressed as the lowest amount on the linearized standard curve, was $6.25 \mathrm{ng} /$ tube. The intra- and inter-assay coefficients of variation were $9.5 \%$ and $15 \cdot 1 \%$, respectively. LH could not be assayed due to unavailability of antisera for thesus monkey $\mathrm{LH}$.

Analysis. The data were analysed by the Wilcoxon Rank Sum test. The $P$ value comparisons were with the pretreatment value for each group.

\section{Results}

\section{Effect on spermiogram and testicular histology}

Androstanediol, at both doses, did not significantly alter the volume of semen ejaculated. Treatment with DHT had no significant effect on semen volume up to Day 40 . On Day 70, semen volume decreased to $0.54 \pm 0.06 \mathrm{ml}$ compared with control values of $1.53 \pm 0.33 \mathrm{ml}(P<0.05)$.

Sperm count in the pretreatment period showed variations among different animals of the same group, which is a normal characteristic for rhesus monkeys. The sperm count was in the range of $175-2021 \times 10^{6} / \mathrm{ml}$ in the 16 animals used. Until Day 40, androstanediol and DHT had no effect on sperm count in any of the animals. On Day 70, a decrease in sperm count was detected in Monkey 1620 of Group I $\left(40 \times 10^{6} / \mathrm{ml}\right)$, Monkeys $1619\left(55 \times 10^{6} / \mathrm{ml}\right)$ and $1576\left(24 \times 10^{6} / \mathrm{ml}\right)$ of Group II and Monkey 1460 of Group III $\left(3.5 \times 10^{6} / \mathrm{ml}\right)$. In the remaining animals, sperm count was within the pretreatment values.

In the pretreatment period, the mean \pm s.e.m. diameter of the seminiferous tubule was $169 \pm 2 \mu \mathrm{m}, 156 \pm 2 \mu \mathrm{m}, 176 \pm 3 \mu \mathrm{m}$ and $174 \pm 3 \mu \mathrm{m}$ in Groups I, II, III and IV, respectively. At the end of treatment, tubular diameter had decreased to $95 \pm 2 \mu \mathrm{m}, 99 \pm 2 \mu \mathrm{m}$, and $119 \pm 2 \mu \mathrm{m}$ in Groups I-III, respectively $(P<0.01$ in all groups compared with pretreatment values of the respective groups), while in Group IV there was no significant change. Increase in intertubular connective tissue was seen in the androgen-treated animals. In Group Iimonkeys the/synchronized $9 \mathrm{AM}$ 
arrangement of germ cells was disrupted and there was a qualitative decrease in the advanced stages of spermatogenesis compared to the control animals. In 3 monkeys in Group II only a few tubules contained spermatozoa and in the remaining tubules there were no advanced stages of spermatogenesis. Spermatogenesis was qualitatively normal in 3 Group III monkeys while in Monkey 1460 with a low sperm count, only a few spermatozoa were seen in the seminiferous tubule.

The percentage of motile spermatozoa decreased in Group I from pretreatment levels of $40-80 \%$ (grade 3, excellent active forward progression) to $10-70 \%$ (grade 2 , moderate forward progression) on Day 40. In Group II pretreatment values were 60-80\% (grade 3) and 10-30\% (grade 2) by Day 40. By Day 70, 2 animals each in Groups I and II showed non-motile (grade 0 ) spermatozoa and in the remaining animals, only $10 \%$ of spermatozoa showed weak forward progressive motility (grade 1). In Group III, 60-80\% of spermatozoa showed grade 3 motility during the pretreatment period, but by Day 40 Monkey 1460 had non-motile spermatozoa and the remaining animals had 10-50\% of spermatozoa showing grade 1 motility. By Day 70, Monkey 1460 had non-motile spermatozoa and motility had decreased to $10-20 \%$ (grade 1) in the remaining animals. In Group IV, no significant change in the percentage of spermatozoa (60-80\%) showing grade 3 motility was seen throughout the study.

The percentage live spermatozoa (70-85\%) did not significantly change in any of the groups during the course of treatment.

The percentage of spermatozoa showing retention of cytoplasmic droplet increased in all treated groups (Table 1).

Table 1. Effects of androgens (Group I, $100 \mu \mathrm{g}$ androstanediol; Group II, $1000 \mu \mathrm{g}$ androstanediol; Group III, $100 \mu \mathrm{g}$ DHT; Group IV, control) on retention of cytoplasmic droplet and coiled tail in rhesus monkey spermatozoa

\begin{tabular}{|c|c|c|c|c|}
\hline \multirow[b]{3}{*}{ Group } & \multicolumn{4}{|c|}{$\%$ Spermatozoa } \\
\hline & \multirow[b]{2}{*}{ Pretreatment } & \multicolumn{3}{|c|}{ Treatment (days) } \\
\hline & & 20 & 40 & 70 \\
\hline \multicolumn{5}{|c|}{$\begin{array}{l}\text { Cytoplasmic } \\
\text { droplet }\end{array}$} \\
\hline I & 1 & $12 \pm 5^{*}$ & $28 \pm 11^{*}$ & $39 \pm 8^{*}$ \\
\hline II & 2 & $16 \pm 2$ & $15 \pm 3 \dagger$ & $19 \pm 5^{*}$ \\
\hline III & $4 \pm 2$ & $18 \pm 2^{*}$ & $41 \pm 13^{*}$ & $26 \pm 10$ \\
\hline IV & $\overline{5}$ & $4 \pm 2$ & $6 \pm 2$ & $8 \pm 1$ \\
\hline \multicolumn{5}{|c|}{ Coiled tail } \\
\hline I & $5 \pm 1$ & $61 \pm 17^{*}$ & $54 \pm 8^{*}$ & $68 \pm 12^{*}$ \\
\hline II & $18 \pm 5$ & $59 \pm 6^{*}$ & $49 \pm 4 \dagger$ & $69 \pm 6^{*}$ \\
\hline III & $4 \pm 2$ & $57 \pm 12 \dagger$ & $81 \pm 3^{*}$ & $73 \pm 8+$ \\
\hline IV & $2 \pm 1$ & $4 \pm 1$ & $10 \pm 5$ & $6 \pm 2$ \\
\hline
\end{tabular}

Values are mean \pm s.e.m. for 4 monkeys/group and 100 spermatozoa were assessed for each monkey.

${ }^{*} P<0.05 ; \dagger P<0.02$, compared with the pretreatment value for the respective group.

In the pretreatment period, there were $2-18 \%$ of spermatozoa with coiled tails. In Group IV the values did not exceed $2-10 \%$ throughout the study, but treatment with androgens increased the percentage spermatozoa with coiled tails (Table 1).

In addition, an increase in the complexity of coiling was also seen. The percentage of spermatozoa with Type A coiling decreased while that showing Type $\mathrm{B}$ and $\mathrm{C}$ coiling increased during treatment. Spermatozoa with Type B coiling were maximum on Day 40 and those with Type C coiling on Day 70 , in all treated groups (Table 2). 
Table 2. Effects of androgens (Group I, $100 \mu \mathrm{g}$ androstanediol; Group II, $1000 \mu \mathrm{g}$ androstanediol; Group III, $100 \mu \mathrm{g}$ DHT; Group IV, control) on different types of tail coiling of rhesus spermatozoa

\begin{tabular}{ccccc}
\hline & \multicolumn{4}{c}{$\%$ Spermatozoa } \\
\cline { 2 - 5 } & & \multicolumn{3}{c}{ Treatment (days) } \\
\cline { 2 - 5 } Group & Pretreatment & 20 & 40 & 70 \\
\hline Type A & & & & \\
coiling & $97 \pm 1$ & $60 \pm 11^{*}$ & $53 \pm 21^{*}$ & $47 \pm 18^{*}$ \\
I & $95 \pm 1$ & $67 \pm 5$ & $40 \pm 8 \dagger$ & $31 \pm 7^{*}$ \\
II & $67 \pm 22$ & $56 \pm 9$ & $28 \pm 12$ & $30 \pm 15$ \\
III & $97 \pm 1$ & $94 \pm 2$ & $97 \pm 1$ & $96 \pm 3$ \\
IV & & & & \\
Type B & $2 \pm 1$ & $28 \pm 6^{*}$ & $37 \pm 20^{*}$ & $29 \pm 12^{*}$ \\
coiling & $3 \pm 1$ & $33 \pm 5$ & $43 \pm 6 \dagger$ & $39 \pm 4^{*}$ \\
I & $5 \pm 2$ & $34 \pm 5 \dagger$ & $64 \pm 12^{*}$ & $40 \pm 7 \dagger$ \\
II & $2 \pm 1$ & $3 \pm 1$ & $1 \pm 1$ & $3 \pm 1$ \\
III & & & & \\
IV & & & & \\
Type C & $1 \pm 1$ & $6 \pm 1^{*}$ & $7 \pm 2^{*}$ & $21 \pm 5^{*}$ \\
coiling & $3 \pm 1$ & $1 \pm 1$ & $15 \pm 5 \dagger$ & $27 \pm 5^{*}$ \\
I & $3 \pm 1$ & $11 \pm 5$ & $8 \pm 2$ & $22 \pm 12^{*}$ \\
II & 1 & 1 & $2 \pm 1$ & 1 \\
III & & & \\
IV & & & & \\
\hline
\end{tabular}

Values are mean \pm s.e.m. for 4 monkeys/group and 100 spermatozoa with a coiled tail were assessed for each monkey. Type A coiling, coiling only at the tip of the endpiece; Type B coiling, endpiece coiled to form whorls; Type $\mathrm{C}$ coiling, midpiece, principal piece and endpiece of spermatozoa involved in coiling.

${ }^{*} P<0.05 ;+P<0.02$ compared with pretreatment value for the respective group.

Androstanediol or DHT did not increase the percentage of spermatozoa showing head-tail separation.

\section{Effect on semen biochemistry}

Concentrations of fructose, GPC and acid phosphatase showed considerable fluctuations in the animals in each group, as is normal for accessory gland secretory activity (Mann \& Lutwak-Mann, 1981). Although pretreatment values of these were numerically different among the groups, the differences were statistically insignificant $(P>0.05)$. The changes with androgen treatment are shown in Fig. 1.

Fructose levels were decreased significantly by Day 70 in Groups I and III. In Group II fructose levels were decreased significantly by Day 40 followed by an increase on Day 70 which was not significantly different from basal level.

The decrease in GPC levels in all treated groups was significant only on Day 70.

Changes in acid phosphatase activity were variable in Group I but in all androgen-treated animals there was a significant decrease by Day 70 .

\section{Effect on hormone concentrations}

Serum testosterone values were decreased in all androgen treated animals within 20 days (Fig. 2). 

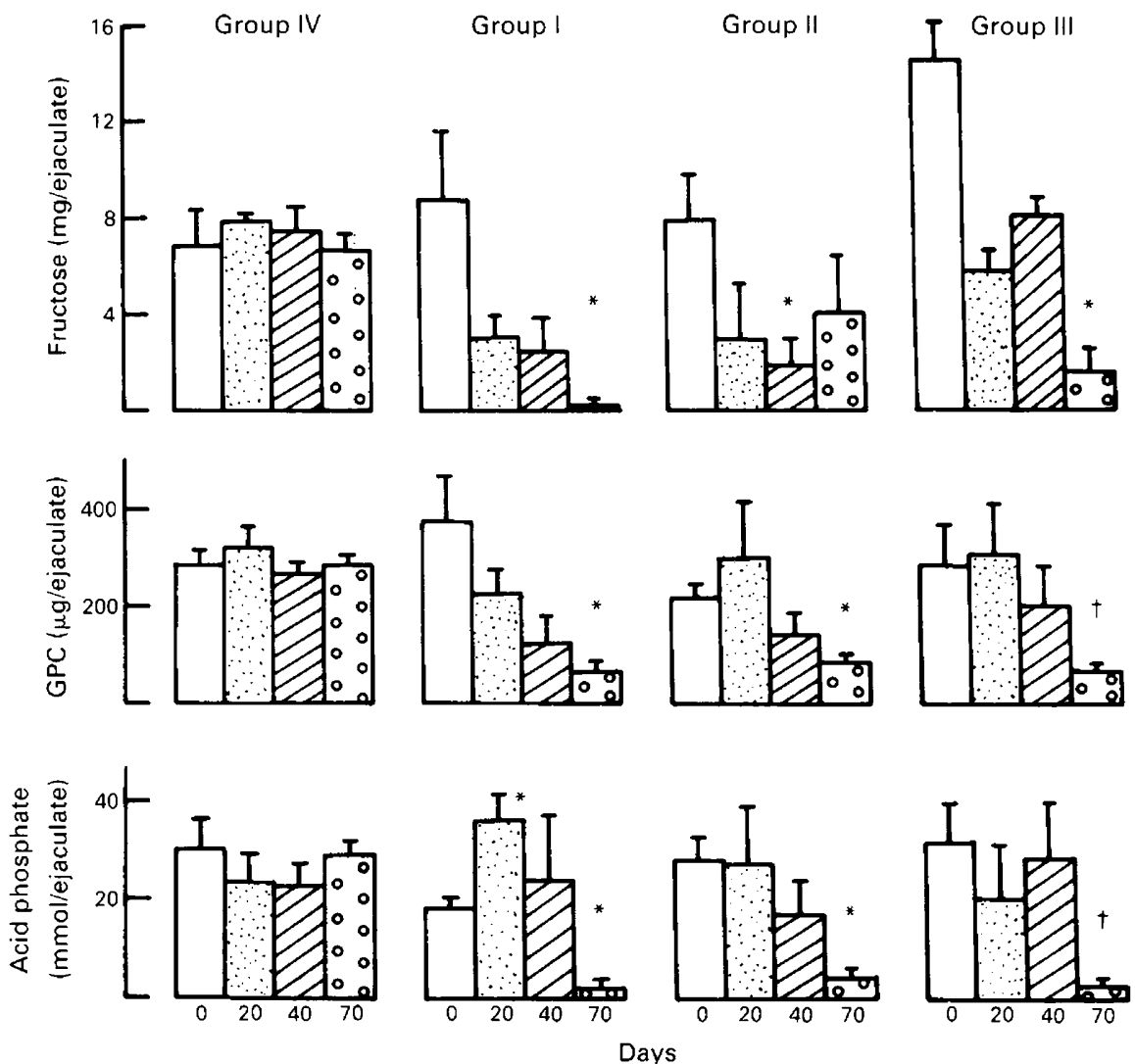

Fig. 1. Effects of androgens (Group I, $100 \mu \mathrm{g}$ androstanediol; Group II, $1000 \mu \mathrm{g}$ androstanediol; Group III, $100 \mu \mathrm{g}$ DHT; Group IV, control) on seminal fructose, GPC and acid phosphatase of rhesus monkeys. Values are mean \pm s.e.m. for 4 monkeys/group. ${ }^{*} P<0.05 ; \dagger P<0.02$ (comparisons are with pretreatment value for the respective group).

The increase in DHT concentrations (Fig. 2) was not significant in Group I monkeys but values were significantly elevated by Day 10 in animals in Groups II and III.

Circulating concentrations of oestradiol and FSH were not altered by treatment with androgens (Fig. 2).

\section{Discussion}

In rhesus monkeys treated with androstanediol, the increase in serum concentrations of DHT reaches levels comparable to those in animals given DHT exogenously and indicates that androstanediol is converted to DHT. The conversion of exogenous androstanediol to DHT has been reported for the rat testis (Purvis et al., 1977), prostate (Bruchovsky, 1971; Becker et al., 1973; Kreig et al., 1975), seminal vesicles (Becker et al., 1973; Kreig et al., 1975) and epididymis (Calandra \& Blaquier, 1973; Djoseland et al., 1976). Conversion of exogenously administered DHT to androstanediol peripherally (Brawer et al., 1983) and intratesticularly (Purvis et al., 1977) has been reported for the rat. Alterations in activities of pituitary and target organs could be due to the action of androstanediol and/or DHT since DHT- and androstanediol-treated animals show similar responses. The adverse effects caused by these two non-aromatizable androgens include alterations in sperm motility, sperm morphology (coiling of tail and retention of cytoplasmic droplet) 

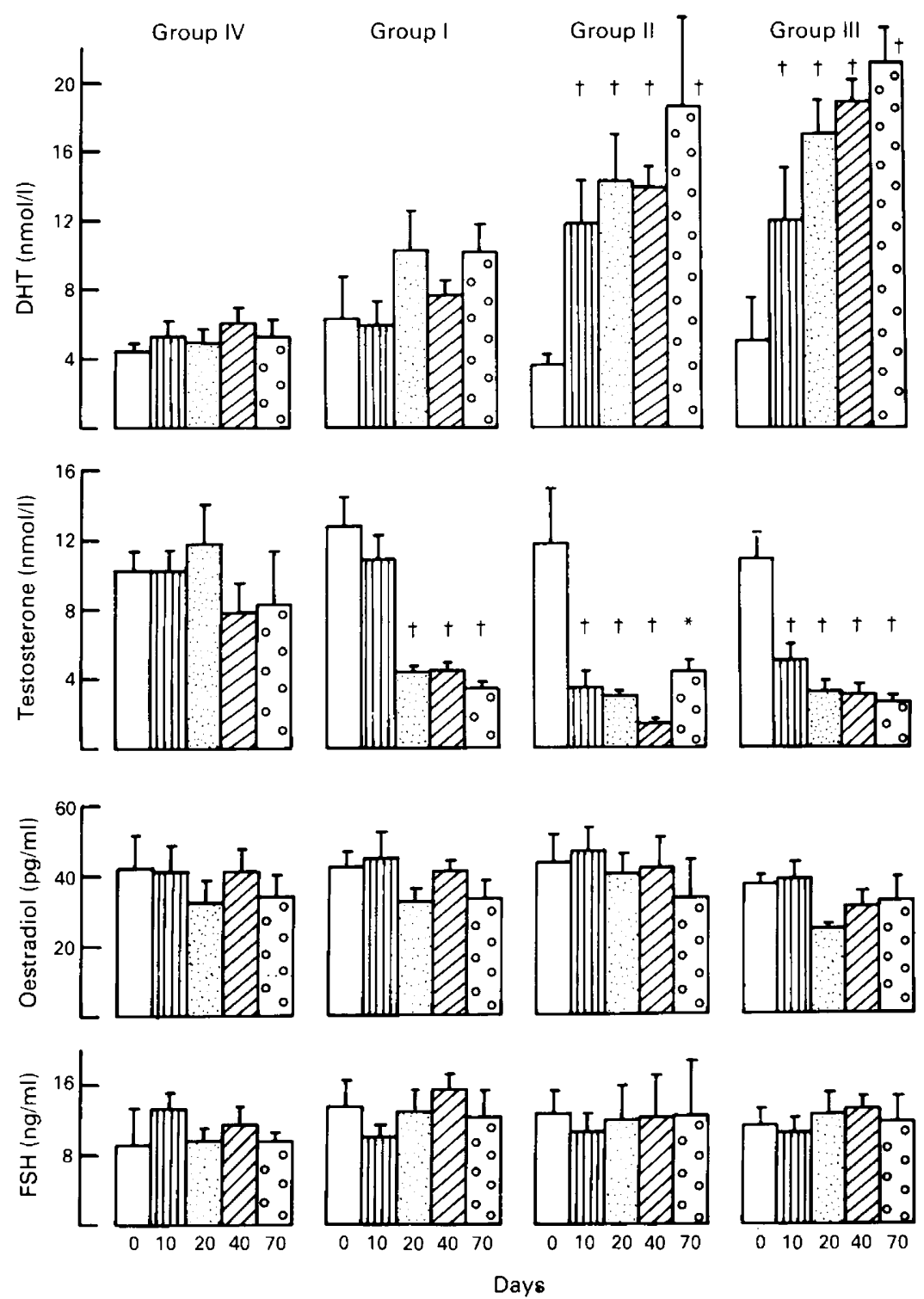

Fig. 2. Effects of androgens (Group I, $100 \mu \mathrm{g}$ androstanediol; Group II, $1000 \mu \mathrm{g}$ androstanediol; Group III, $100 \mu \mathrm{g}$ DHT; Group IV, control) on serum hormone concentrations in rhesus monkeys. Values are mean \pm s.e.m. for 4 monkeys/group. ${ }^{*} P<0.05 ; \dagger P<0.02$ (comparisons are with pretreatment value for the respective group).

and testicular histology without significantly altering sperm counts. The androgens were administered for one spermatogenic cycle and only 3 semen samples were collected during this period which may be responsible for the lack of effect on sperm counts. It is also possible that intratesticular concentrations of testosterone, the levels of which could not be determined due to ethical considerations, are not suppressed to values that would disrupt spermatogenesis drastically in treated animals although circulating testosterone concentrations may be reduced to near undetectable levels. The effects of long-term treatment with DHT larenow beingcinvestigated.at 04/26/2023 10:33:09AM 
The increase in percentage of ejaculated spermatozoa with coiled tails and their retention of cytoplasmic droplets raises the possibility that sperm maturation is adversely affected. The migration and loss of the cytoplasmic droplet are considered an index of sperm maturation; its retention in a significant percentage of spermatozoa is considered indicative of pathology of sperm maturation and infertility (Lagerloff, 1934; Bedford, 1975). It is possible that exogenous administration of androstanediol and DHT have down regulated androgen receptors in the epididymis and accessory glands, resulting in suppression of the functions of these organs. Steroid receptors, like glucocorticoid receptors, undergo down regulation in intact animals and cells grown in culture after administration of glucocorticoids (Gustafsson et al., 1987). The abnormalities of spermatozoa may be a consequence of altered secretion of biochemical constituents such as proteins/ glycoproteins which are known to be involved in sperm maturation. Wickings \& Nieschlag (1980) reported abnormalities in the sperm neck and tail in rhesus monkeys immunized with FSH. The coiling of the sperm tail in androstanediol- and DHT-treated animals may be the cause of the decreased motility observed in our study.

The decrease in serum testosterone values in androstanediol and DHT treated animals could be due to a fall in LH via the negative feedback action on hypothalamus-pituitary axis (Juneja et al., 1976; Purvis et al., 1977). The reason for increase in serum testosterone concentration on Day 70 over that on Day 40 in Group II is not clear. This may be the cause of increase in fructose to near pretreatment values on Day 70 seen in that group.

Suppression of serum testosterone concentrations in treated monkeys was not accompanied by a decrease in oestradiol values. It is known that when testicular contribution to oestradiol is abolished, as in testicular failure, oestrogens formed from adrenal androgens cause feminization of the male (Siiteri \& MacDonald, 1973). It is therefore possible that adrenal androgens may be responsible for maintaining oestradiol concentrations in androgen-treated monkeys although experimental evidence to support this premise cannot be provided.

Androstanediol and DHT had no effect on the ejaculatory response of the animals and hence can maintain normal sexual behaviour despite reduced levels of testosterone. It is known that DHT alone can maintain sexual behaviour in castrated rhesus monkeys (Phoenix, 1974).

The fact that androstanediol and DHT cause severe abnormalities of spermatozoa, maintain normal sexual behaviour and do not hyperstimulate prostatic function suggests their potential use in the regulation of fertility in the male.

This study was supported by the Indian Council of Medical Research.

\section{References}

Bajaj, J.S. \& Madan, R. (1983) Regulation of male fertility. In International Symposium on Research on the Regulation of Human Fertility, pp. 729-767. Eds E. Diczfalusy \& A. Diczfalusy. Stockholm, Sweden.

Becker, H., Grabosch, E., Hoffman, C. \& Voigt, K.D. (1973) Metabolism and mode of action of androgens in target tissues of male rats. III. Metabolism of $5 \alpha$ androstane-3,17-dione, of $5 \alpha$-androstane-3 $\alpha, 17 \beta$-diol and of $5 \alpha$-androstane- $3 \beta, 17 \beta$-diol, in target organs and peripheral tissues. Acta endocr., Copenh. 73, 407-416.

Bedford, J.M. (1975) Maturation, transport and fate of spermatozoa in epididymis. In Handbook of Physiology, Sect. 7, Vol. V, pp. 303-317. Eds D. W. Hamilton \& R. O. Greep. American Physiological Society, Washington, D.C.

Belsey, M.A., Eliasson, R., Gallegos, A.J., Moghissi,
K.S., Paulsen, C.A. \& Prasad, M.R.N. (1980) Laboratory Manual for the Examination of Human Semen and Semen-Cervical Mucus Interaction. Press Concern, Singapore.

Brawer, J., Schipper, H. \& Robaire, R. (1983) Effects of long term androgen and estradiol exposure on the hypothalamus. Endocrinology. 112, 194-199.

Brenner, P.F., Guerrero, R., Cekan, Z. \& Diczfalusy, E. (1973) Radioimmunoassay method of six steroids in human plasma. Steroids 22, 775-794.

Bruchovsky, N. (1971) Comparison of metabolites formed in rat prostate following the in vivo administration of seven natural androgens. Endocrinology. 89, 1212-1222.

Calandra, R.S. \& Blaquier, J.A. (1973) Receptors for androgens in rat epididymis. Interaction with $5 \alpha$ androstane-3a,17ק-diol. J. Steroid Biochem. 4, 525 4394 ded from Bioscientifica.com at 04/26/2023 10:33:09AM via free access 
Djoseland, O., Hastings, C.D. \& Hansson, V. (1976) Androgen metabolism by rat epididymis. Metabolic conversion of ${ }^{3} \mathrm{H}-5 \alpha$-androstane- $3 \alpha, 17 \beta$-diol, in vivo. Steriods 28, 585-596.

Gustafsson, J.A., Carlstedt-Duke, J., Poellinger, L., Okret, S., Wikstrom, A.C, Bronnegard, A. \& Agnati, L. (1987) Biochemistry, molecular biology and physiology of the glucocorticoid receptor. Endocr. Rev. 8, 185-234.

Hastings, C.D., Brekke, I., Attramadal, A. \& Hansson, V. (1980) Physico-chemical characterization of soluble $3 \alpha$-hydroxysteroid oxidoreductase in the rat testis and prostate. Int. J. Androl. 3, 72-81.

Juneja, H.S., Motta, M., Massa, R., Zanisi, M. \& Martini, L. (1976) Feedback control of gonadotrophin secretion in male. In Sperm Action, pp. 163-173. Ed. P. O. Hubinont. S. Karger, Basel.

Khan, S.A., Froysa, B. \& Diczfalusy, E. (1984) Biological and immunological characterization of purifed follicle-stimulating hormone preparations from monkey pituitaries. $J$. med. Primatol. 13, 269-282.

Kreig, M., Horst, H.-J. \& Sterba, M.-L. (1975) Binding and metabolism of $5 \alpha$-androstane- $3 \alpha, 17 \beta$-diol and of $5 \alpha$-androstane- $3 \beta, 17 \beta$-diol in the prostate, seminal vesicles and plasma of male rats; studies in vivo and in vitro. J. Endocr. 64, 529-538.

Lagerloff, N. (1934) Morphologishe untersuchungen uber Veranderungen im spermabild und in den hoden bei bullen mitverminderter oder aufgehobener fertilitat. Acta pathol. microbiol. scand., Suppl. 19, $1-254$.

Lindhart, K. \& Walter, K. (1965) Phosphatases (phosphomonoesterases). In Methods of Enzymatic Analysis, p. 783. Ed. H. U. Bergmeyer. Academic Press, New York.

Lindner, H.R. \& Mann, T. (1960) Relationship between the content of androgenic steroids in the testis and the secretory activity of the seminal vesicles of the bull. J. Endocr. 21, 341-360.

Mann, T. \& Lutwak-Mann, C. (1981) Male Reproductive Function and Semen. Springer-Verlag, Berlin.

Mastroianni, L., Jr \& Manson, W.A., Jr (1963) Collection of monkey semen by electroejaculation. Proc. Soc. exp. Biol. Med. 112, 1025-1027.
Payne, A.H., Kawano, A. \& Jeffe, R.B. (1973) Formation of dihydrotestosterone and other $5 \alpha$-reduced metabolites by isolated seminiferous tubules and suspension of interstitial cells in a human testis. J. clin. Endocr. Metab. 37, 448-453.

Phoenix, C.H. (1974) Effect of dihydrotestosterone on sexual behaviour of castrated male rhesus monkeys. Physiol. Behav. 12, 1045-1055.

Purvis, K., Calandra, R., Haug, E. \& Hansson, V. (1977) $5 \alpha$-reduced androgens and testicular function in the immature rat; effects of $5 \alpha$-androstan-17\%-ol-3 one (DHT) propionate and $5 \alpha$-androstane-3,17 $\beta$-diol. Molec. cell. Endocrinol. 7, 203-219.

Rivarola, M.A., Podesta, E.J., Chemes, H.E. \& Aguilar, D. (1973) In vitro metabolism of testosterone by whole human testis, isolated seminiferous tubules and interstitial tissue. J. clin. Endocr. Metab. 37, $454-460$.

Schmidt, H., Giba-Tziampiri, O., Rotteck, G.V. \& Voigt, K.D. (1973) Metabolism and mode of action of androgens in target tissue of male rats. IV. Mode of action of $5 \alpha$-androstane-3,17-dione, $5 \alpha$-androstane$3 \alpha, 17 \beta$-diol and of $5 \alpha$-androstane- $3 \beta, 17 \beta$-diol at a celluiar level on seminal vesicles and prostates of rat. Acta endocr., Copenh. 73, 599-611.

Siiteri, P.K. \& MacDonald, P.C. (1973) Role of extraglandular estrogen in human endocrinology. In Handbook of Physiology, Sect. 7, Vol. II, pp. 615-629. Eds R. O. Greep \& E. B. Astwood. American Physiological Society, Washington, D.C.

Sjoberg, B., de la Torre, B., Hedman, M., Falkay, G. \& Diczfalusy, E. (1979) Circadian variation in systemic hormone levels in healthy men. $J$. endocr. Invest. 2, $131-140$.

Troen, P. (1977) Physiology and pharmacology of testosterone. In Hormonal Control of Male Fertility, pp. 1-12. Ed. D. J. Patanelli. US Department of Health, Education and Welfare, Washington, D.C.

White, I.G. (1959) Studies on the estimation of glycerol, fructose and lactic acid with particular reference to semen. Aust. J. exp. Biol. 37, 441-450.

Wickings, E.J. \& Nieschlag, E. (1980) Suppression of spermatogenesis over two years in rhesus monkeys actively immunised with follicle-stimulating hormone. Fert. Steril. 34, 269-274.

Received 5 July 1989 